\title{
Progesterone and Estrogen Regulate Alzheimer-Like Neuropathology in Female 3xTg-AD Mice
}

\author{
Jenna C. Carroll, ${ }^{1,2}$ Emily R. Rosario, ${ }^{1,2}$ Lilly Chang, ${ }^{3}$ Frank Z. Stanczyk, ${ }^{3}$ Salvatore Oddo, ${ }^{4}$ Frank M. LaFerla, ${ }^{4}$ and \\ Christian J. Pike ${ }^{2}$ \\ ${ }^{1}$ Neuroscience Graduate Program, ${ }^{2}$ Davis School of Gerontology, ${ }^{3}$ Department of Obstetrics and Gynecology, University of Southern California, Los Angeles, \\ California 90089, and ${ }^{4}$ Department of Neurobiology and Behavior, University of California, Irvine, Irvine, California 92697
}

\begin{abstract}
Estrogen depletion in postmenopausal women is a significant risk factor for the development of Alzheimer's disease (AD), and estrogen-based hormone therapy may reduce this risk. However, the effects of progesterone both alone and in combination with estrogen on AD neuropathology remain unknown. In this study, we used the triple transgenic mouse model of $\mathrm{AD}(3 \mathrm{xTg}-\mathrm{AD})$ to investigate the individual and combined effects of estrogen and progesterone on $\beta$-amyloid $(\mathrm{A} \beta)$ accumulation, tau hyperphosphorylation, and hippocampal-dependent behavioral impairments. In gonadally intact female $3 \times \mathrm{Tg}-\mathrm{AD}$ mice, $\mathrm{AD}$-like neuropathology was apparent by 3 months of age and progressively increased through age 12 months, a time course that was paralleled by behavioral impairment. Ovariectomy-induced depletion of sex steroid hormones in adult female 3xTg-AD mice significantly increased $\mathrm{A} \beta$ accumulation and worsened memory performance. Treatment of ovariectomized $3 \times \mathrm{Tg}-\mathrm{AD}$ mice with estrogen, but not progesterone, prevented these effects. When estrogen and progesterone were administered in combination, progesterone blocked the beneficial effect of estrogen on $\mathrm{A} \beta$ accumulation but not on behavioral performance. Interestingly, progesterone significantly reduced tau hyperphosphorylation when administered both alone and in combination with estrogen. These results demonstrate that estrogen and progesterone independently and interactively regulate $\mathrm{AD}$-like neuropathology and suggest that an optimized hormone therapy may be useful in reducing the risk of $\mathrm{AD}$ in postmenopausal women.
\end{abstract}

Key words: estrogen; progesterone; Alzheimer's disease; $\beta$-amyloid; tau; Y-maze

\section{Introduction}

Alzheimer's disease $(\mathrm{AD})$ is an age-related neurodegenerative disorder characterized by accumulation of $\beta$-amyloid $(A \beta)$ and neurofibrillary tangles, progressive neuron loss, and cognitive deficits (Hardy and Selkoe, 2002). Abundant evidence suggests that the depletion of the sex steroid hormones estrogen and progesterone (P4) at menopause is a significant risk factor for the development of $\mathrm{AD}$ in women (Paganini-Hill and Henderson, 1994, 1996; Tang et al., 1996; Kawas et al., 1997). Furthermore, prospective and case-control studies have demonstrated that hormone therapy (HT) can reduce the risk of $\mathrm{AD}$ in women (Paganini-Hill and Henderson, 1996; Tang et al., 1996; Kawas et al., 1997). Given this background, findings from the Women's Health Initiative Memory Study (WHIMS) demonstrating a higher incidence of dementia in subjects receiving estrogenbased HT in the absence (Espeland et al., 2004) and presence (Rapp et al., 2003; Shumaker et al., 2003) of progestin were unexpected. The WHIMS findings raised many important issues, highlighting the needs to better understand the role of estrogen and progesterone in AD pathogenesis and to optimize HT.

One of the important issues raised by the WHIMS trial is the

Received June 15, 2007; revised Sept. 27, 2007; accepted 0ct. 5, 2007.

This work was funded by National Institutes of Health Grants AG026572, AG00093 (J.C.C.), and NS52143 (E.R.R.)

Correspondence should be addressed to Christian J. Pike, Davis School of Gerontology, University of Southern California, Los Angeles, CA 90089-0191. E-mail: cjpike@usc.edu.

DOI:10.1523/JNEUROSCI.2718-07.2007

Copyright $\odot 2007$ Society for Neuroscience $\quad 0270-6474 / 07 / 2713357-09 \$ 15.00 / 0$ role of progestogens in HT (Brinton, 2004; Craig et al., 2005). Although the many beneficial actions of estrogen in the brain are well established, the roles of progesterone, both alone and in combination with estrogen, remain incompletely defined. Some evidence suggests that progesterone improves hippocampal-dependent spatial memory (Roof et al., 1994) and protects neurons in some (Roof et al., 1994; Alkayed et al., 2000; Hoffman et al., 2003; De Nicola et al., 2006) but not all (Azcoitia et al., 1999; Toung et al., 2004) rodent models of neuronal injury. Similarly, coadministration of estrogen and progesterone rescues neuronal loss in some rodent paradigms of neural injury (Azcoitia et al., 1999; Toung et al., 2004) but not others (Rosario et al., 2006a). The effects of progesterone, both alone and in combination with estrogen, on neuropathology in animal models of $\mathrm{AD}$ are not known.

To begin investigating the individual and combined effects of estrogen and progesterone on $\mathrm{AD}$-like neuropathology, we used the triple transgenic mouse model of $\mathrm{AD}(3 \mathrm{xTg}-\mathrm{AD})$, which exhibits many features of AD neuropathology (Oddo et al., 2003b). In this study, we evaluated the effects of experimental manipulation of estrogen and progesterone levels in adult female $3 \times \mathrm{Tg}$ - $\mathrm{AD}$ mice on the development of $\mathrm{A} \beta$ accumulation, tau hyperphosphorylation, and hippocampal-dependent memory performance.

\section{Materials and Methods \\ Animals}

Colonies of 3xTg-AD (Oddo et al., 2003b) and background strain, wildtype (WT) (C57BL/6/129S; The Jackson Laboratory, Bar Harbor, ME) mice were bred and maintained at the University of Southern California 


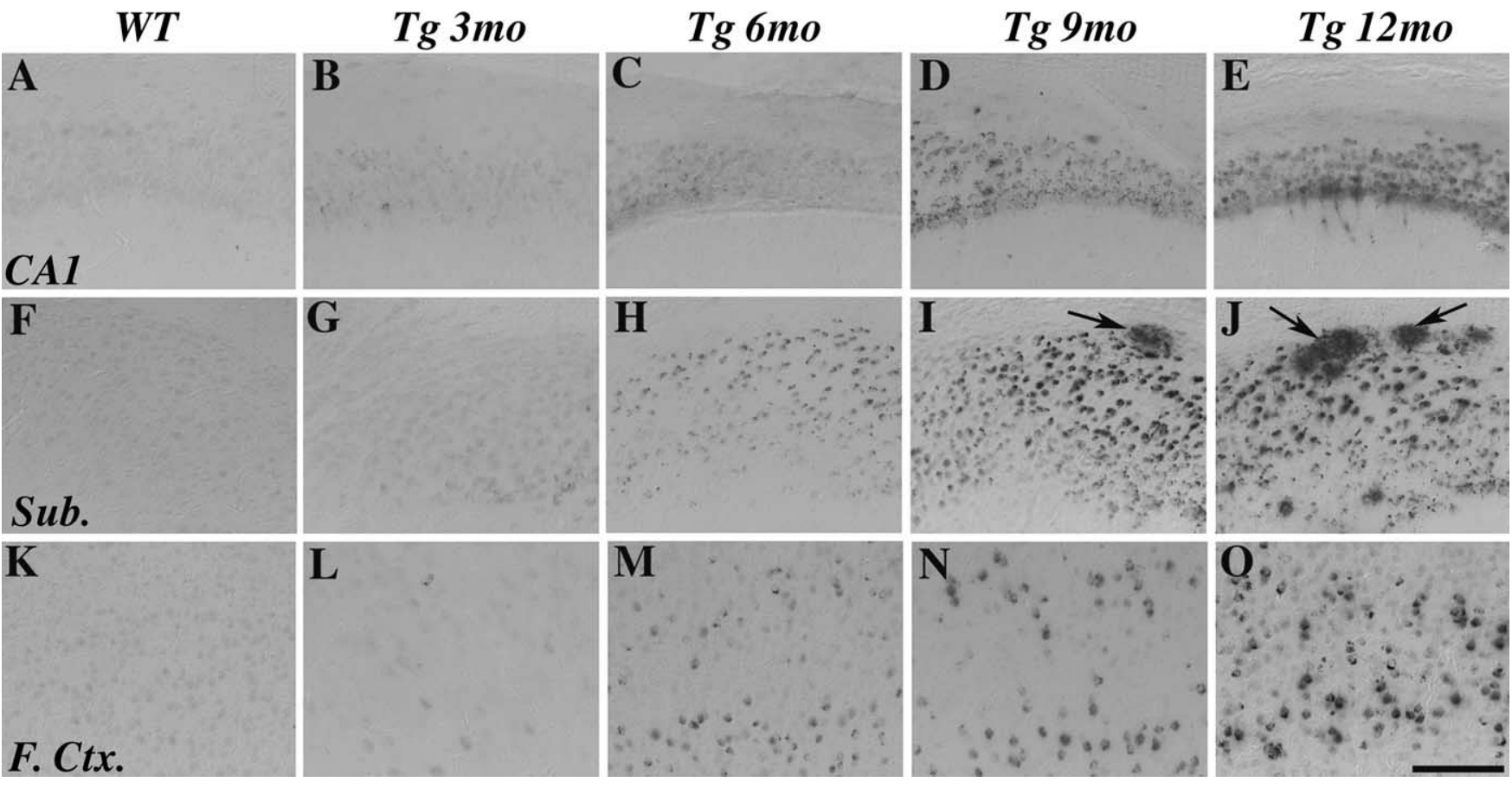

Figure 1. Age-related increase in $A \beta$ immunoreactivity. Representative images show $A \beta$-IR in hippocampus $(A 1(\boldsymbol{A}-\boldsymbol{E})$, subiculum (Sub.; $\boldsymbol{F}-\boldsymbol{J})$, and layers IV and $V$ of frontal cortex (F.Ctx.; $\boldsymbol{K}-\boldsymbol{0}$ ) from female $3 \times \operatorname{XT}$-AD mice at ages 3 months $(\boldsymbol{B}, \boldsymbol{G}, \boldsymbol{L}), 6$ months $(\boldsymbol{C}, \boldsymbol{H}, \boldsymbol{M}), 9$ months $(\boldsymbol{D}, \boldsymbol{I}, \boldsymbol{N})$, and 12 months $(\boldsymbol{E}, \boldsymbol{J}, \boldsymbol{O})$ and from WT female mice at age 6 months $(\boldsymbol{A}, \boldsymbol{F}, \boldsymbol{K})$. Specific $A \beta$-IR is not observed in WT mice but in 3xTg-AD is apparent intraneuronally by age 3 months and extracellularly (arrows) beginning at age 9 months. Scale bar, $100 \mu \mathrm{m}$.

in accordance with National Institutes of Health guidelines on use of laboratory animals and an approved protocol by the University of Southern California (Los Angeles, CA) Institutional Animal Care and Use Committee. Female mice used in these studies were housed individually on $12 \mathrm{~h}$ light/dark cycles and provided ad libitum access to food and water.

\section{Experimental design}

This study consists of three experiments that were conducted using separate groups of animals, except when indicated.

Treatment groups for experiment 1 . To investigate the age-related development of $\mathrm{AD}$-like neuropathology in female $3 \mathrm{xTg}$ - $\mathrm{AD}$ mice, gonadally intact females were randomly assigned to one of the following four groups ( $n=7$ per group) representing age at death: $3,6,9$, and 12 months. WT mice age 6 months were used as a comparison group.

Treatment groups for experiment 2 . To investigate the development of AD-like neuropathology after estrogen manipulation, 3-month-old female 3xTg-AD and WT mice were assigned to one of the following three treatment groups ( $n=7$ per group): sham ovariectomized (OVX), OVX, and OVX plus $17 \beta$-estradiol (E2). Mice were bilaterally OVX and immediately implanted with a subcutaneous, continuous-release $90 \mathrm{~d}$ pellet (Innovative Research of America, Sarasota FL) containing either $0.25 \mathrm{mg}$ of $\mathrm{E} 2$ (OVX+E2 group) or placebo (sham OVX and OVX groups). Animals in the sham OVX group were the same mice that comprised the 6 month group in experiment 1 . All animals in experiment 2 were killed at age 6 months, 3 months after the initiation of hormone manipulations.

Treatment groups for experiment 3. To investigate the development of AD-like neuropathology after progesterone manipulation, 3-month-old female 3xTg-AD and WT mice were divided into the following treatment groups ( $n=7$ per group): OVX, OVX $+\mathrm{P} 4$, and OVX $+\mathrm{E} 2+\mathrm{P} 4$. Mice were bilaterally OVX, immediately implanted with a subcutaneous, continuous-release $90 \mathrm{~d}$ pellet containing $25.0 \mathrm{mg}$ of $\mathrm{P} 4$, both $0.25 \mathrm{mg}$ of $\mathrm{E} 2$ and $25 \mathrm{mg}$ of $\mathrm{P} 4$, or vehicle (Innovative Research of America), and killed at 6 months of age.

The hormone pellet doses used in experiments 2 and 3 have been shown to produce serum levels of estrogen and progesterone in the physiological range (Pomp et al., 1995; Kadish and Van Groen, 2002; Shultz et al., 2004). All hormone-treated mice were killed at 6 months of age, 3 months after initiation of hormone treatment. For all experiments, animals were behaviorally tested on the morning they were killed. Afterward, they were deeply anesthetized $(100 \mathrm{mg} / \mathrm{kg}$ sodium pentobarbital), transcardially perfused with cold PBS, and decapitated. To confirm the efficacy of hormone treatments, (1) uteri were dissected, blotted, and weighed, and (2) blood was collected for analysis of serum hormone levels. Hemibrains were immersion fixed in $4 \%$ paraformaldehyde for $48 \mathrm{~h}$ and then stored in $4^{\circ} \mathrm{C}$ in $\mathrm{PBS} / 1 \%$ sodium azide until use.

\section{Serum hormone levels}

$\mathrm{E} 2$ and $\mathrm{P} 4$ serum levels were measured using radioimmunoassay (RIA) as described previously (Slater et al., 2001).

\section{Immunohistochemistry}

Fixed hemibrains were blocked, sectioned $(40 \mu \mathrm{m})$ exhaustively in the horizontal plane using a vibratome, and then processed for immunohistochemistry using a standard protocol (Pike, 1999; Rosario et al., 2006b). Briefly, every eighth section ( $\sim 12$ per brain) was immunostained using antibodies directed against (1) $\mathrm{A} \beta$ (71-5800 $\mathrm{A} \beta, 1: 300$ dilution; Zymed Laboratories, San Francisco CA), (2) A $\beta$ precursor protein C-terminal fragments (CTFs) (CT20, 1:16,000 dilution; Calbiochem, San Diego, CA), or (3) hyperphosphorylated tau (AT8, 1:1000 dilution; Pierce, Rockford, IL) using ABC Vector Elite and diaminobenzidine kits (Vector Laboratories, Burlingame, CA). Antigen unmasking treatment, consisting of 5 min rinse in $99 \%$ formic acid, was performed to enhance $A \beta$ immunoreactivity (IR) (Cummings et al., 2002).

\section{Quantification of immunohistochemistry}

Immunohistochemistry was quantified using two different methods by a researcher blinded to experimental condition. First, levels of positive immunoreactivity for $\mathrm{A} \beta$ and CTF antibodies were determined by immunohistochemistry load technique (Cummings et al., 2002; Rosario et al., 2006b). Load values were determined from selected $420 \times 330 \mu \mathrm{m}$ fields of immunolabeled sections that were captured and digitized using a video capture system [black and white CCD camera coupled to an Olympus Optical (Tokyo, Japan) BX40 upright microscope]. Using NIH Image software 1.61, digital grayscale images were converted into binary positive/negative data using a constant threshold limit. The percentage of 
positive pixels (i.e., IR area) was quantified for each image and then averaged across images for each brain region in each animal to generate immunoreactive load values. Quantified fields were selected systematically using a predetermined pattern to maximize analysis of immunoreactivity in each brain region. For hippocampus CA1 and subiculum, every eighth horizontal section was analyzed across the entire hippocampus (a total of $\sim 12$ sections per brain), beginning with a randomly selected section from the first eight sections of dorsal hippocampus. In hippocampus CA1, the capture frame was centered over the pyramidal layer with the first captured field corresponding to the narrow zone that marks the division between the end of the regio inferior (CA2/3) and the start of regio superior (CA1) as defined by West et al. (1991). Progressing across CA1 toward the subiculum, the first three adjacent but nonoverlapping fields were captured for load analysis. In the subiculum, we similarly captured two adjacent nonoverlapping fields per section beginning at the sharp transition from the large pyramidal cells of the CA1 to the smaller cells of the presubiculum (West et al., 1991). In the frontal cortex, fields were captured from every sixth coronal section beginning rostrally with the appearance of somatosensory cortex (Franklin and Paxinos, 1997) for a total of six sections per brain. For each section, the frame was centered over layers $4-5$, and five adjacent nonoverlapping fields were captured beginning in cingulate cortex area 1 and progressing laterally to somatosensory cortex (Franklin and Paxinos, 1997).

Second, the numbers of $\mathrm{A} \beta$ deposits and AT8-immunoreactive neurons were counted, as described previously (Rosario et al., 2006b). Because of the relatively low numbers of both $\mathrm{A} \beta$ deposits and AT8immunoreactive cells, we counted all immunoreactive objects meeting criteria within the combined CA1 hippocampus and subiculum regions, as defined above, for every 11th section in each animal. AT8immunoreactive neurons were defined as cells showing strong AT8 immunolabeling over most of the cell surface. $A \beta$ deposits were defined as diffuse or dense extracellular accumulations of $A \beta$ immunoreactivity with approximate diameter at least twice the size of a neuron (to prevent misidentification of intraneuronal $\mathrm{A} \beta$ immunoreactivity).

\section{Spontaneous alternation behavior}

Mice were tested for working memory using spontaneous alternation behavior (SAB) in a Y-maze, as described previously (Rosario et al., 2006b). The maze was constructed from black-colored Plexiglas (short arms $\mathrm{A}$ and $\mathrm{B}, 6 \times 5 \times 3$ inches; long arm C, $8 \times 5 \times 3$ inches). Each animal was placed in arm $\mathrm{C}$ of the maze and allowed to explore freely for $8 \mathrm{~min}$. The total numbers of arm choices and alternations were recorded. An arm choice was defined as both forepaws and hindpaws fully entering the arm. The maze was cleaned with $70 \%$ ethanol between animals to minimize odor cues. SAB score was calculated as the proportion of alternations (an arm choice differing from the previous two choices) to the total number of alternation opportunities (total arm entries, two) (King and Arendash, 2002).

\section{Statistical analyses}

To statistically evaluate treatment effects, raw data were first analyzed by ANOVA and then subjected to between-group comparisons using the Fisher's least significant difference test. Effects achieving $95 \%$ probability (i.e., $p<0.05$ ) were interpreted as statistically significant.

\section{Results}

\section{Experiment 1: development of neuropathology in female} 3xTg-AD mice

Age-related increase in $A \beta$ accumulation

As a first step in determining the effects of E2 and P4 on AD-like neuropathology in female $3 \mathrm{xTg}-\mathrm{AD}$ mice, we assessed the agerelated development of $\mathrm{A} \beta$ accumulation in gonadally intact female $3 \mathrm{xTg}$-AD mice at $3,6,9$, and 12 months of age. A $\beta$ accumulation was evaluated in three hormone-responsive brain regions affected in AD: CA1 of hippocampus, subiculum, and frontal cortex. We observed intraneuronal A $\beta$-IR in all three brain regions that was apparent at low levels by age 3 months and increased through age 12 months (Fig. 1). In frontal cortex, $A \beta$-IR
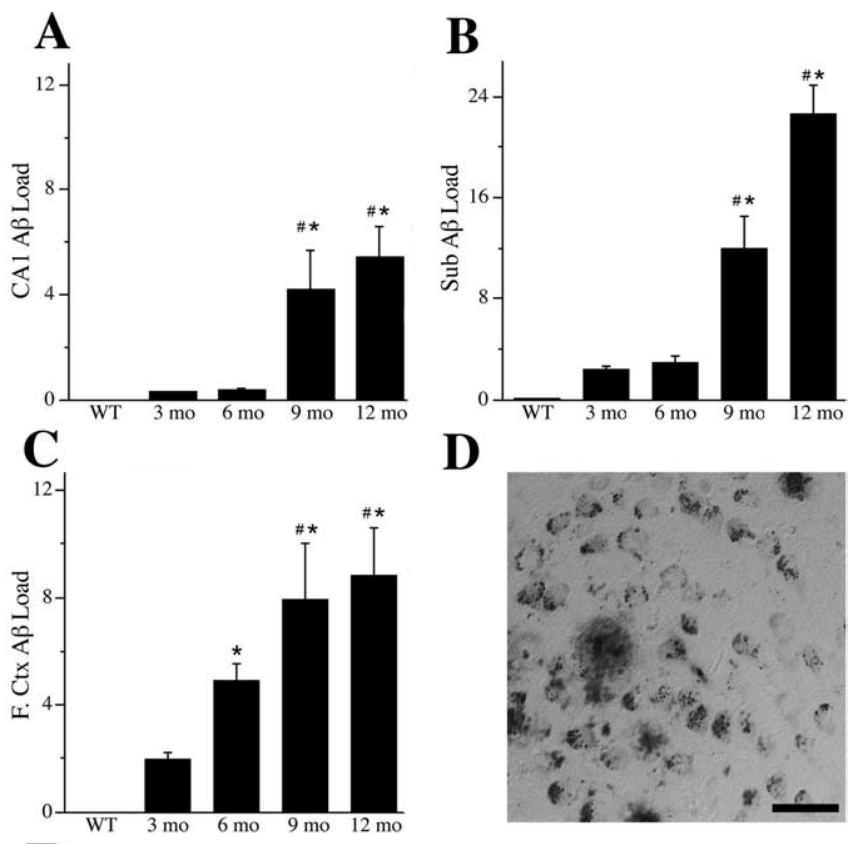

D

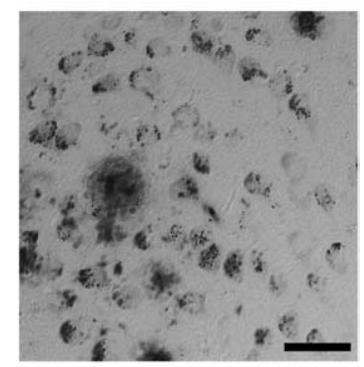

Figure 2. Quantification of age-related increase in $A \beta$ accumulation. $A \beta$ load values were quantified in hippocampus $C A 1(\boldsymbol{A})$, subiculum (Sub.; $\boldsymbol{B})$, and layers IV and V of frontal cortex (F.Ctx.; $\boldsymbol{C}$ ) from WT mice at 6 months of age and from female 3xTg-AD mice at 3, 6, 9, and 12 months of age. Data represent mean \pm SEM A $\beta$ load values from two to three nonoverlapping fields per section, $6-12$ sections per brain ( $n=7$ per condition). ANOVA showed significant between group differences in $A \beta$ load in hippocampus CA1 $(F=5.98, p=0.008)$, subiculum $(F=31.85, p<0.001)$, and frontal cortex $(F=7.6, p=0.008) . D, A \beta$-IR also included extracellular $A \beta$ deposits that were observed primarily in subiculum. Scale bar, $50 \mu \mathrm{m}$. $\boldsymbol{E}$, Data show mean \pm SEM counts of extracellular $A \beta$ deposits in subiculum and hippocampus CA1 from 12 sections per animal at ages $3,6,9$, and 12 months in 3xTg-AD mice and age 6 months in WT mice. A significant age-related increase in $A \beta$ deposits was observed in $3 x T g-A D$ mice $(F=$ $9.70, p<0.001)$. ${ }^{*} p<0.05$ compared with 3 months; ${ }^{*} p<0.05$ compared with 6 months.

was primarily restricted to layers IV and $\mathrm{V}$ and in hippocampus was most prominent in CA1 pyramidal layer. Relatively lower levels of $\mathrm{A} \beta$-IR were observed in basolateral amygdala and entorhinal cortex (data not shown). Only light, nonspecific immunolabeling was observed in WT female mice in all brain regions at age 6 months (Fig. $1 A, F, K$ ) and later ages (data not shown). Load quantification of $\mathrm{A} \beta$-IR showed that $\mathrm{A} \beta$ levels were greatest in subiculum, followed by frontal cortex, then hippocampus CA1 (Fig. 2). A $\beta$ accumulated most quickly in frontal cortex and exhibited the strongest trend for continued accumulation beyond age 12 months in subiculum (Fig. 2). In addition to accumulating intraneuronally, $A \beta$-IR was also observed in the form of extracellular, plaque-like deposits beginning at age 9 months and strongly increasing at age 12 months (Fig. 2D,E). Extracellular $\mathrm{A} \beta$ deposits were observed almost exclusively in subiculum through age 12 months, although they were also occasionally observed in hippocampus CA1 and entorhinal cortex. 
To confirm that our evaluation of $\mathrm{A} \beta \mathrm{pa}-$ thology reflects amyloidogenic species of $A \beta$ rather than non-amyloidogenic CTFs of amyloid precursor protein, we examined CTF-IR and quantified CTF load in the subiculum. We observed that CTF-IR exhibited markedly different staining pattern compared with A $\beta$-IR; CTF-IR was localized to the periphery of the cell body (Fig. $3 H$ ), whereas $\mathrm{A} \beta$-IR was localized throughout the cell body, often with a punctate distribution (Fig. 3I). High levels of CTF load were observed at similar levels in female $3 x \mathrm{Tg}-\mathrm{AD}$ mice across all ages examined (Fig. $3 B-F$ ). Comparably low levels of CTF load were seen in 6-month-old female WT mice (Fig. $3 A, G)$.

Age-related increase in tau hyperphosphorylation

To further investigate the development of $\mathrm{AD}$-like neuropathology in female $3 \mathrm{xTg}$-AD mice, we assessed the age-related progression of tau hyperphosphorylation. We quantified the number of cells strongly immunoreactive with the AT8 antibody, which recognizes pathological phosphorylation of tau at Ser 202 and 305 that is associated with $\mathrm{AD}$ (Goedert et al., 1995). Intensely stained AT8-immunoreactive neurons were reliably detected, albeit in low numbers, at 9 months of age and increased in abundance through 12 months of age (Fig. 4).AT8-immunoreactive neurons were most common in the subiculum and observed occasionally in hippocampus CA1 but were not found in frontal cortex by age 12 months.

Age-related decline in spontaneous alternation behavior

Finally, we evaluated working memory in female $3 \times \mathrm{Tg}-\mathrm{AD}$ mice by assessing performance of hippocampal-dependent $\mathrm{SAB}$ in the Y-maze. SAB performance of female $3 \mathrm{xTg}-\mathrm{AD}$ mice at ages 3 and 6 months was not significantly impaired compared with WT female mice. However, SAB performance was significantly and increasingly impaired at 9 and 12 months of age (Fig. $5 A$ ). In contrast, female WT mice did not show a significant age-related decline in $\mathrm{SAB}$ performance through age 12 months (data not shown). To ensure that observed changes in $\mathrm{SAB}$ in $3 \mathrm{xTg}-\mathrm{AD}$ mice were not the result of changes in activity level, we measured the number of arm entries in the Y-maze. SAB per-

formance was not associated with the number of arm entries (Fig. 5B).

Experiment 2: effect of estrogen on neuropathology in female 3xTg-AD mice

Confirmation of estrogen treatment

To investigate the effects of hormone status on the development of $\mathrm{AD}$-like pathology, female $3 \mathrm{xTg}$-AD mice were depleted of sex

$\operatorname{Tg} 9 \mathrm{mo}$ Scale bar, $50 \mu \mathrm{m}$.
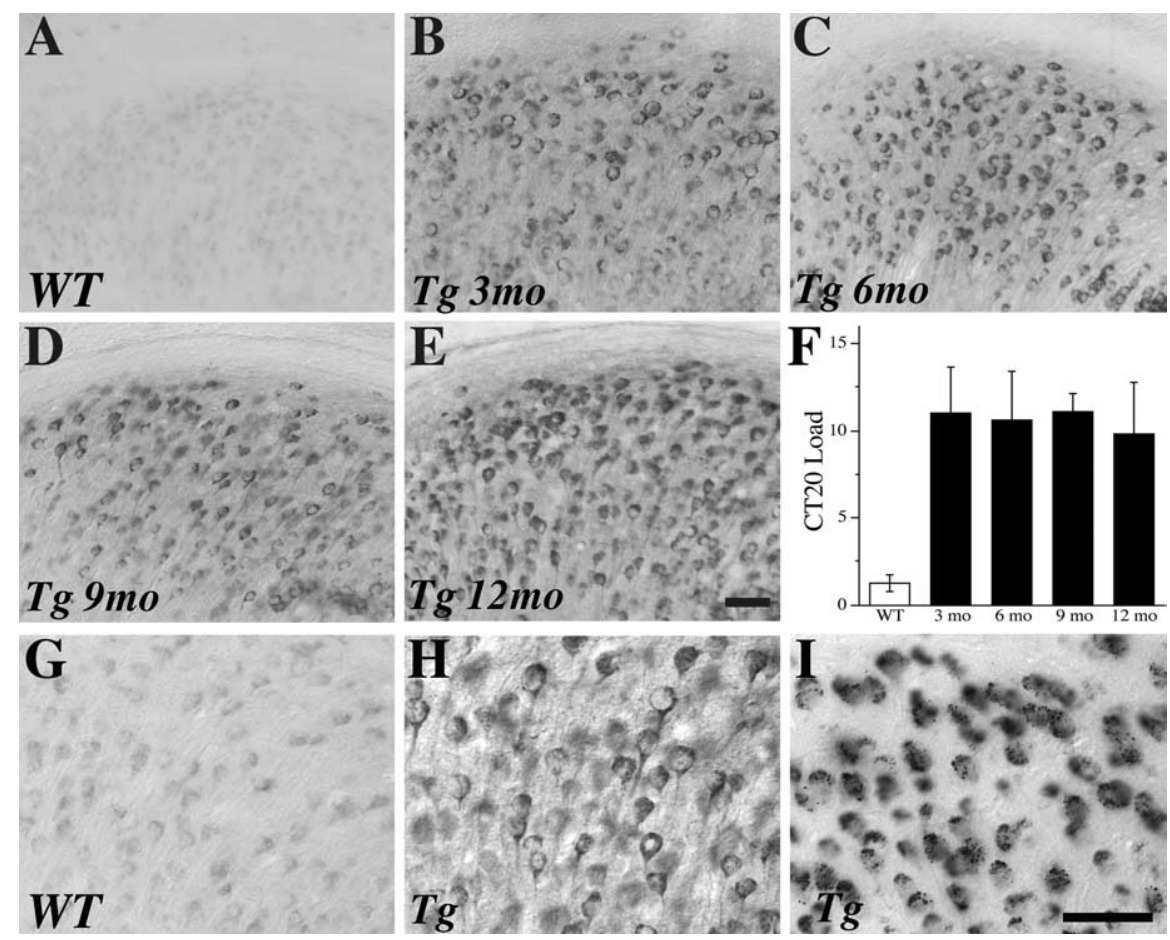

Figure 3. CTF levels do not change across conditions in 3xTg-AD mice. Representative images show (TF-IR in the subiculum of 6-month-old WT female mice $(\boldsymbol{A})$ and female $3 \times \operatorname{xT}$-AD mice at 3 months $(\boldsymbol{B}), 6$ months $(\boldsymbol{C}), 9$ months $(\boldsymbol{D})$, and 12 months $(\boldsymbol{E})$ of age. $F$, Quantification of (TF load across conditions shows high CTF levels in all 3xTg-AD groups that does not significantly vary by age $(F=0.14, p=0.94)$. A similar, extranuclear distribution of (TF-IR is observed at high magnification ( $400 \times)$ in WT mice $(\boldsymbol{G})$ and 3xTg-AD mice $(\boldsymbol{H})$ that qualitatively differs from the more uniform and often punctate appearance of $A \beta$-IR in 3xTg-AD mice $(\boldsymbol{I})$.
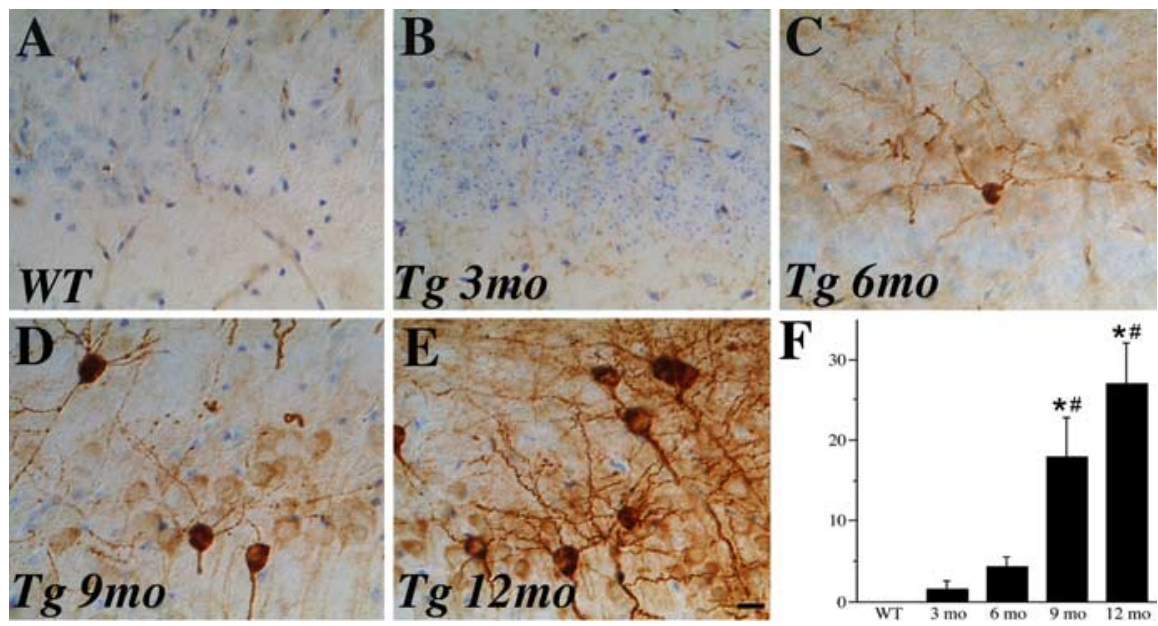

Figure 4. Age-related increase in tau hyperphosphorylation. Tau hyperphosphorylation is absent in 6-month-old WT mice $(\boldsymbol{A})$ but exhibits an age-related increase in female $3 x T g-A D$ mice at 3 months $(\boldsymbol{B}), 6$ months $(\boldsymbol{C}), 9$ months $(\boldsymbol{D})$, and 12 months $(\boldsymbol{E})$ of age. Representative images show sections immunostained with AT8 antibody (dark brown label), which recognizes abnormally phosphorylated tau, and counterstained with cresyl violet. Scale bar, $50 \mu \mathrm{m}$. F, Quantification of numbers of intensely AT8immunoreactive neurons in hippocampus (A1 and subiculum demonstrates the magnitude of this effect $(F=5.59, p=0.007)$. ${ }^{*} p<0.05$ relative to 3 months; ${ }^{*} p<0.05$ relative to 6 month $3 x T g-A D$ groups. 

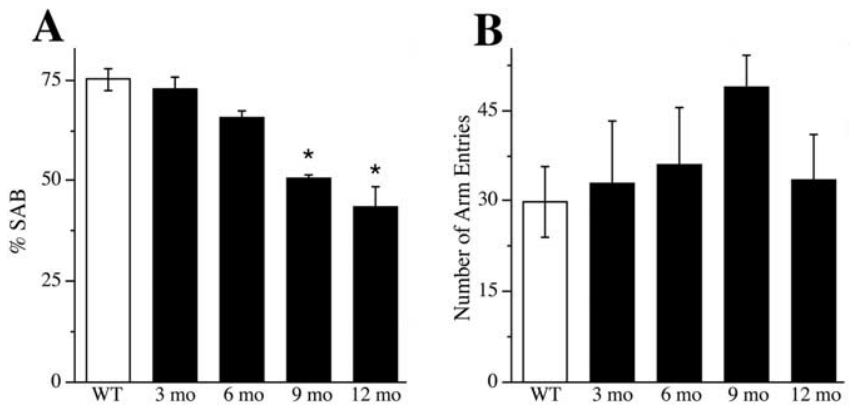

Figure 5. Age-related decline in spontaneous alternation behavior. Hippocampaldependent working memory performance in female $3 x T g-A D$ mice was investigated by assessing $S A B$ in a Y-maze. $A$, Compared with WT mice (open bars), SAB performance in female $3 x T g-A D$ mice (filled bars) showed impairment that began at age 6 months and became statistically significant at ages 9 and 12 months $(F=16.2, p<0.001) .{ }^{*} p<0.05$ compared with WT. $\boldsymbol{B}$, The number of arm entries, measured as a negative control for activity level, did not significantly vary across conditions $(F=1.14, p=0.37)$.

$p=0.04)$. The OVX group had significantly lower E2 levels than the sham OVX group ( $p=0.016$ ), whereas the OVX+E2 group had serum E2 levels significantly higher than the OVX group $(p=0.012)$ but not significantly greater than the sham OVX group $(p=0.81)$. Similar results were observed with uterine weights (sham OVX, $86.6 \pm 9.6 \mathrm{mg}$; OVX, $15.5 \pm 1.9 \mathrm{mg}$; $\mathrm{OVX}+\mathrm{E} 2,162.2 \pm 31.1 \mathrm{mg} ; F=12.86, p<0.001)$. OVX-induced hormone depletion caused a significant decrease in uterine weight compared with the sham OVX condition ( $p=0.027)$, and E2 treatment caused a significant increase compared with both the OVX $(p<0.001)$ and sham OVX $(p=0.01)$ groups.

\section{Estrogen regulates $A \beta$ accumulation}

If $\mathrm{E} 2$ beneficially regulates $\mathrm{A} \beta$ accumulation, then OVX-induced hormone depletion should increase $\mathrm{A} \beta$ accumulation, whereas E2 treatment of OVX animals should prevent this increase. To investigate this hypothesis, female $3 \mathrm{xTg}-\mathrm{AD}$ mice were assessed for $A \beta$ accumulation at age 6 months, after the 3 month period of hormone manipulation. Consistent with our prediction, we observed that, compared with the sham OVX group, the OVX group exhibited a robust increase in $\mathrm{A} \beta$ load in hippocampus CA1, subiculum, and frontal cortex (Fig. $6 B, F, J$ ). E2 treatment in OVX animals partially attenuated the increased $A \beta$ load in subiculum and entirely prevented it in hippocampus CA 1 and frontal cortex (Fig. $6 C, G, K$ ). The second measure of $\mathrm{A} \beta$ pathology, $\mathrm{A} \beta$ plaque number, was not counted in E2-manipulated mice because of the small number of plaques present in 6-month-old animals. To confirm that estrogen regulation of $A \beta$-IR reflects amyloidogenic species of $\mathrm{A} \beta$ rather than CTFs, we quantified and compared CTF-IR in E2-manipulated mice. As expected, we observed that CTF load was not significantly different across the sham OVX, OVX, and OVX $+\mathrm{E} 2$ groups $(F=0.36, p=0.70)$.

Estrogen regulation of tau hyperphosphorylation

To further investigate estrogen regulation of $\mathrm{AD}$-like neuropathology, we also determined the effect of estrogen status on levels of tau hyperphosphorylation by counting the combined number of AT8-immunoreactive neurons in subiculum and hippocampus CA1 of E2-manipulated female 3xTg-AD mice. We found that the number of AT8-immunoreactive neurons was not significantly altered in the OVX group or the OVX + E2 group $(F=$ 2.29, $p=0.13$ ) (Fig. 7).

Estrogen effects on spontaneous alternation behavior $\mathrm{Next}$, we investigated the possibility that $\mathrm{E} 2$ regulation of $\mathrm{AD}$-like neuropathology in female $3 \mathrm{xTg}$-AD mice may also affect memory function as measured by SAB performance in the $\mathrm{Y}$-maze test. We found that OVX resulted in a significant decline in SAB performance and that E2 treatment of OVX animals reversed this effect, restoring $\mathrm{SAB}$ performance to the level of sham OVX animals (Fig. 8A). These effects were unrelated to general activity levels because the numbers of arm entries were similar across treatment groups (Fig. $8 \mathrm{~B}$ ). To confirm that the effects of hormone manipulations on $\mathrm{SAB}$ reflected underlying neuropathology rather than direct hormone effects on SAB, we also evaluated the effects of OVX with and without E2 treatment on SAB in WT female mice at age 6 months. There were no significant differences across the sham OVX, OVX, and OVX+E2 groups of WT female mice in $\mathrm{SAB}$ performance (Fig. $8 \mathrm{C}$ ).

\section{Experiment 3: effect of progesterone on neuropathology in female 3xTg-AD mice \\ Confirmation of progesterone treatment}

To investigate the effects of progesterone on the development of AD-like neuropathology, female 3xTg-AD mice were depleted of endogenous sex steroid hormones by OVX at age 3 months and then treated immediately with either placebo (OVX group) or continuous $\mathrm{P} 4$ in the absence $(\mathrm{OVX}+\mathrm{P} 4$ group) or presence of continuous $\mathrm{E} 2(\mathrm{OVX}+\mathrm{E} 2+\mathrm{P} 4$ group) for a period of 3 months. Efficacy of P4 treatment was confirmed directly by measuring serum P4 levels using RIA. Effects on uterine weight were also determined. Serum levels of P4 resulting from hormone treatment were within the expected physiological range and significantly greater than observed in gonadally intact female mice (sham OVX, $1.6 \pm 1.1 \mathrm{ng} / \mathrm{ml} ; \mathrm{OVX}+\mathrm{P} 4,7.3 \pm 0.5 \mathrm{ng} / \mathrm{ml}$; $\mathrm{OVX}+\mathrm{E} 2+\mathrm{P} 4,3.9 \pm 0.7 \mathrm{ng} / \mathrm{ml} ; F=4.59, p=0.003)$. Evaluation of uterine weights $(\mathrm{OVX}, 17.1 \pm 1.4 \mathrm{mg}$; OVX $+\mathrm{P} 4,40.3 \pm 5.1$ mg; OVX+E2+P4, $108.1 \pm 20.4 \mathrm{mg} ; F=12.84, p<0.001$ ) showed that $\mathrm{P} 4$ treatment had a mild uterotrophic effect that did not reach statistical significance ( $p=0.19)$, although the E2 $+\mathrm{P} 4$ treatment had a significant proliferative effect $(p<0.001)$ compared with OVX mice.

Progesterone attenuates the effect of estrogen on $A \beta$ accumulation If $\mathrm{P} 4$ shares with $\mathrm{E} 2$ the ability to reduce $\mathrm{A} \beta$ accumulation, then $\mathrm{P} 4$ treatment would be predicted to prevent the increase in $\mathrm{A} \beta$ accumulation resulting from OVX-induced hormone depletion. However, we observed no significant difference in $\mathrm{A} \beta$ load between the OVX and OVX $+\mathrm{P} 4$ conditions in hippocampus CA1, subiculum, and frontal cortex (Fig. 9). We also investigated the clinically relevant issue of whether $\mathrm{P} 4$ affects the actions of E2 to reduce the OVX-induced increase in $\mathrm{A} \beta$ accumulation. We observed that, unlike the $\mathrm{A} \beta$-lowering effect of continuous $\mathrm{E} 2$ alone (Fig. 6), combined continuous treatment with E2 and P4 treatment for 3 months did not significantly affect $A \beta$ accumulation in hippocampus CA1, subiculum, or frontal cortex compared with the OVX condition (Fig. 9). There were also no significant differences in CTF load across treatment groups $(F=0.11, p=$ $0.90)$.

\section{Progesterone regulates tau hyperphosphorylation}

We also investigated the effect of P4 treatments on tau hyperphosphorylation by counting the number of AT8immunoreactive neurons in hippocampus CA1 and subiculum of female 3xTg-AD mice. Interestingly, P4 treatment robustly decreased the number of AT8-immunoreactive neurons compared with the OVX group, an effect that persisted when $\mathrm{P} 4$ was delivered in combination with E2 (Fig. 10). 
Progesterone effects on spontaneous alternation behavior

Finally, we investigated whether the P4 treatments affected $\mathrm{SAB}$ performance. Compared with the poor SAB performance of OVX 3xTg-AD mice (Fig. 8), we observed that the OVX $+\mathrm{E} 2+\mathrm{P} 4$ group but not the OVX $+\mathrm{P} 4$ group showed improved performance (Fig. 11A). As expected, SAB did not reflect changes in activity level, because the number of arm entries was not significantly different across the $3 \times \mathrm{Tg}-\mathrm{AD}$ treatment groups $($ Fig. $11 B)$. To ensure that SAB performance was not significantly affected by direct effects of female sex steroid hormones, we evaluated $\mathrm{SAB}$ in WT mice in the OVX, OVX $+\mathrm{P} 4$, and $\mathrm{OVX}+\mathrm{E} 2+\mathrm{P} 4$ conditions and found no significant between group differences (Fig. 11C).

\section{Discussion}

In this study, we investigated the relationship between the sex steroid hormones estrogen and progesterone and the development of AD-like neuropathology in the 3xTg-AD mouse model of AD. Consistent with previous findings (Oddo et al., 2003a), we observed that $\mathrm{AD}$-like pathologies in female $3 \times \mathrm{Tg}-\mathrm{AD}$ mice, including $\mathrm{A} \beta$ accumulation, tau hyperphosphorylation, and deficits in working memory, appear within a few months of age and progressively worsen. Specifically, intraneuronal $A \beta$ accumulation occurred first, followed by tau hyperphosphorylation, and then impaired SAB performance. Significantly, we found that experimental depletion of endogenous estrogen and progesterone by OVX exacerbated these pathologies, suggesting independent and or combined actions of these hormones in regulating AD-like pathology. Consistent with a protective role of estrogen, we found that E2 treatment in OVX mice prevented the worsening in $\mathrm{A} \beta$ accumulation and SAB impairment. However, estrogen status was not associated with significant changes in tau phosphorylation. In contrast, $\mathrm{P} 4$ treatment in OVX mice did not affect either $\mathrm{A} \beta$ accumulation or SAB, although it did strongly reduce tau hyperphosphorylation. When $\mathrm{P} 4$ treatment was combined with $\mathrm{E} 2$, the protective effect of $\mathrm{E} 2$ on $\mathrm{A} \beta$ accumulation was attenuated, but both reduced tau hyperphosphorylation and improved $\mathrm{SAB}$ were observed compared with OVX mice. These data, which represent the first report of progesterone effects in an animal model of $\mathrm{AD}$, implicate both separate and combined actions of estrogen and progesterone in regulation of $\mathrm{AD}$-like pathologies.

Our results support the hypothesis that estrogen protects against development of AD-like neuropathology. Similar to our findings, other studies have reported increased $\mathrm{A} \beta$ levels after OVX in WT guinea pigs (Petanceska et al., 2000) and in transgenic mouse models of AD (Zheng et al., 2002). Furthermore, E2 treatment has been associated with decreased brain levels of $A \beta$ in guinea pigs (Petanceska et al., 2000) as well as in the $\mathrm{APP}_{\mathrm{SWE}}$ (mice expressing the Swedish form of amyloid precursor protein) (Levin-Allerhand et al., 2002), Tg2576 (Zheng et al., 2002), and Tg2576×PS1 (transgenic 2576 mice expressing presenilin 1) (Zheng et al., 2002) AD mouse models. In contrast, other studies have reported that neither OVX nor E2 treatment significantly altered A $\beta$ levels in the PDAPP (mice expressing the Parkinson's
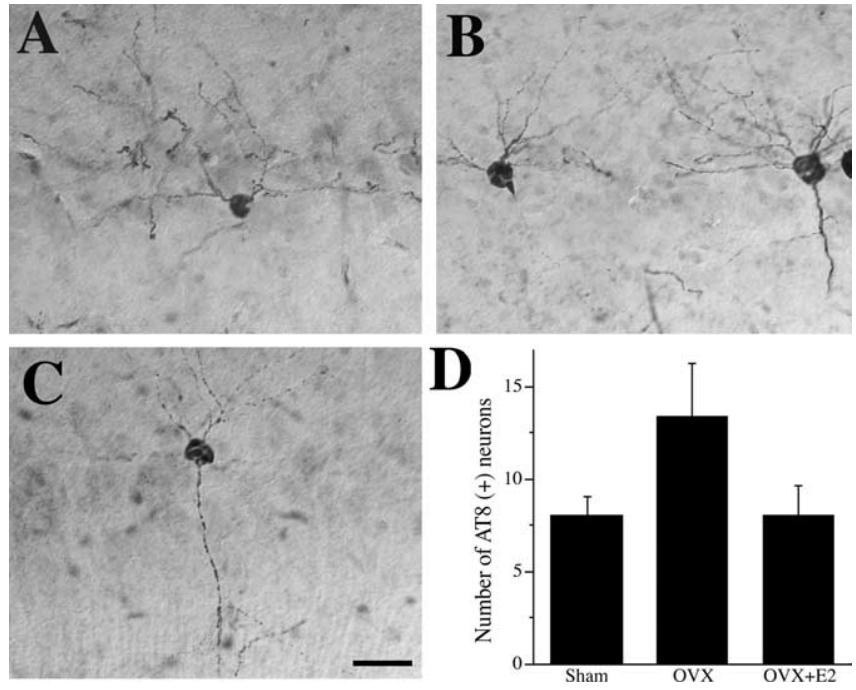

Figure 7. E2 regulation of tau hyperphosphorylation. Representative images of AT8-IR (counterstained with cresyl violet) show neurons with abnormal tau phosphorylation in female $3 x \operatorname{Tg}$-AD mice at age 6 months in sham $0 \mathrm{VX}(\boldsymbol{A}), 0 \mathrm{VX}(\boldsymbol{B})$, and OVX + E2 (C) conditions. Scale bar, $50 \mu \mathrm{m}$. D, Quantification of numbers of intensely AT8-immunoreactive cells in hippocampus CA1 and subiculum show that neither OVX nor E2 treatment significantly altered tau phosphorylation $(F=2.29, p=0.13)$.

disease form of amyloid precursor protein) (Green et al., 2005), $\mathrm{APP}_{\text {SWE }} \times \mathrm{PS} 1$ (Heikkinen et al., 2004), and APP23 (Yue et al., 2005) transgenic mouse models of $A D$. It is unclear why estrogen status is associated with $\mathrm{A} \beta$ levels in some models but not others. There are several factors that vary between the studies and may contribute to the inconsistent findings. One potentially important difference across studies has been varying methods of $\mathrm{A} \beta$ quantification, each of which preferentially detects different pools of $A \beta$ ranging from soluble monomeric $A \beta$ to oligomeric and deposited forms. The effect of estrogen on the various $A \beta$ forms has yet to be determined. In this study, we found that 
A

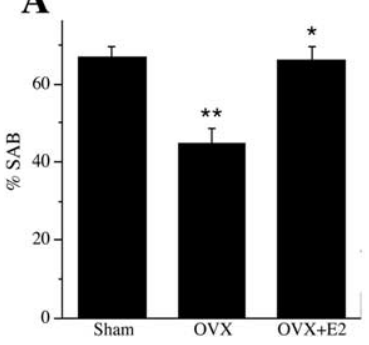

B

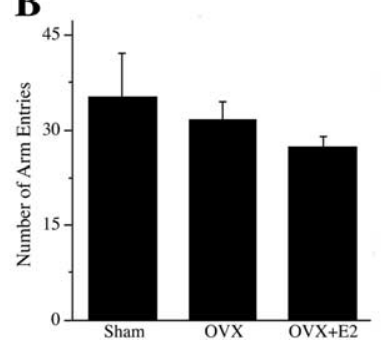

C

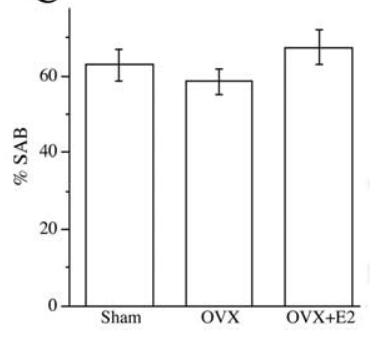

Figure 8. E2 regulates spontaneous alternation behavior. Estrogen status significantly affected $S A B$ performance in 6-monthold female $3 \times T g-A D$ mice but not in age-matched WT female mice. $A$, Compared with the sham OVX group (Sham) of 3xTg-AD mice, the OVX group exhibited significantly impaired $S A B$ that was prevented in the $0 V X+E 2$ group $(F=14.48, p<0.001)$. ${ }^{*} p<$ 0.05 from relative to $0 \mathrm{VX} ;{ }^{* *} p<0.05$ relative to sham. $B$, The number of arm entries in the task did not significantly differ across $3 x \operatorname{Tg}-\mathrm{AD}$ treatment groups $(F=1.87, p=0.19) . C$, In contrast to results in $3 \times \mathrm{Tg}$-AD mice, there was no significant difference in $\mathrm{SAB}$ performance across sham, OVX, and OVX+E2 groups in WT mice $(F=0.94, p=0.41)$.
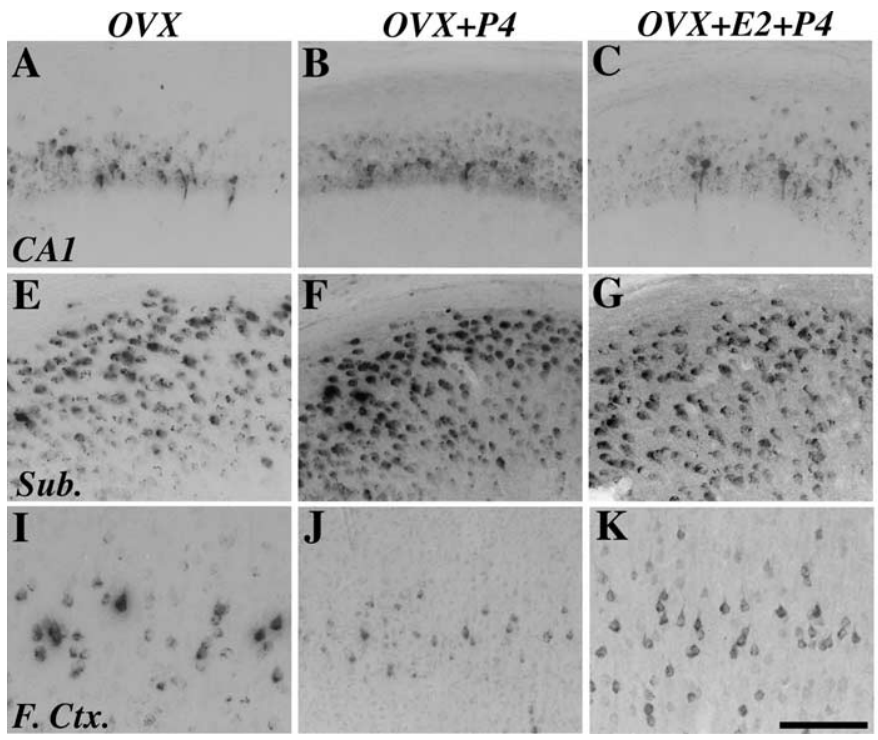

Figure 9. $\quad P 4$ attenuates the effects of $E 2$ on $A \beta$ accumulation. $A \beta$-IR was visualized in female $3 x T g-A D$ mice at age 6 months in the OVX $(\boldsymbol{A}, \boldsymbol{E}, \boldsymbol{I}), \mathrm{OVX}+\mathrm{P} 4(\boldsymbol{B}, \boldsymbol{F}, \boldsymbol{J})$, and OVX $+\mathrm{E} 2+\mathrm{P} 4(\boldsymbol{C}, \boldsymbol{G}, \boldsymbol{K})$ groups in hippocampus CA1 $(\boldsymbol{A}-\boldsymbol{C})$, subiculum (Sub.; $\boldsymbol{E}-\boldsymbol{G})$, and frontal cortex (F.Ctx.; $\boldsymbol{I}-\boldsymbol{K}$ ), as shown in representative images. Scale bar, $100 \mu \mathrm{m}$. Data demonstrate that mean \pm SEM A $\beta$ load did not differ significantly across treatment groups in hippocampus $C A 1(F=0.85, p=0.45)(D)$, subiculum $(F=2.10, p=0.15)$ $(\boldsymbol{H})$, and frontal cortex $(F=0.58, p=0.57)(\boldsymbol{L})$.

estrogen decreases $A \beta$ as determined by immunoreactive load method, which measures $A \beta$ that accumulates both intracellularly and extracellularly and presumably reflects relatively insoluble $\mathrm{A} \beta$ forms. Because oligomeric $\mathrm{A} \beta$ is increasingly recognized as pathologically significant (Walsh et al., 2005), we have begun to consider the potential hormone regulation of this $A \beta$ pool. In preliminary slot blot studies using an oligomeric-specific anti-A $\beta$ antibody, we observed elevated levels of oligomeric $A \beta$ in aged female 3xTg-AD mice (our unpublished observations), consistent with a previous report (Oddo et al., 2006a). However, we did not consistently observe oligomeric $\mathrm{A} \beta$ in female $3 \mathrm{xTg}-\mathrm{AD}$ mice at age 6 months and thus were unable to evaluate whether hormonal status affects levels of oligomeric $A \beta$. Future studies will need to address not only how sex steroid hormones regulate $A \beta$ but also which $\mathrm{A} \beta$ pool(s) they regulate.

Beyond investigating estrogen effects, this study is the first to directly examine the effects of progesterone on AD-like neuropathology. The most significant findings from this study are the observations that, although continuous $\mathrm{P} 4$ treatment by itself had no effect on $\mathrm{A} \beta$ accumulation, $\mathrm{P} 4$ attenuated the beneficial effect
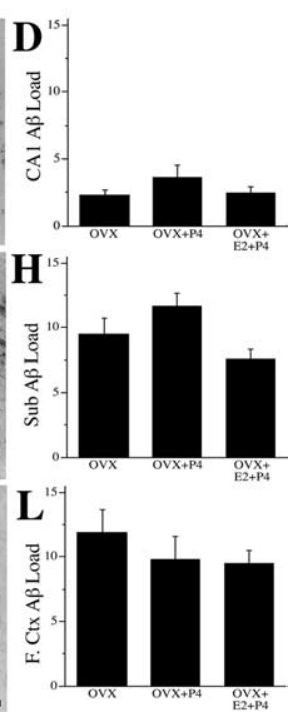

of $\mathrm{E} 2$ treatment on lowering $\mathrm{A} \beta$ accumulation in female $3 \times \mathrm{Tg}-\mathrm{AD}$ mice. Our finding that $\mathrm{P} 4$ lacks independent action but attenuates E2 action is consistent with recent observations in other paradigms. For example, we recently reported that, although $\mathrm{P} 4$ treatment in female OVX rats did not affect the extent of kainateinduced neuron loss, it completely blocked E2 neuroprotection (Rosario et al., 2006a). Similarly, continuous P4 treatment has been reported to inhibit E2mediated increases in neurotrophin expression (Bimonte-Nelson et al., 2004) and spatial memory performance (Bimonte-Nelson et al., 2006). One particularly interesting component of this relationship with hypothesized clinical relevance is the effect of continuous versus cyclic P4 treatment. Previous work by Gibbs (2000) demonstrated that hippocampal cholinergic activity in OVX female rats was increased by cyclic treatment with $\mathrm{E} 2$ and $\mathrm{P} 4$ but decreased by continuous treatment with E2 and P4. Potential differences between continuous and cyclic $\mathrm{P} 4$ treatment in 3xTg-AD mice are currently under study.

In addition to the hormone-mediated effects on $A \beta$ accumulation, we also observed that progesterone significantly regulated tau hyperphosphorylation in female $3 \mathrm{xTg}-\mathrm{AD}$ mice. Although we observed a statistically nonsignificant trend of reduced tau hyperphosphorylation in the presence of estrogen, we found that P4 treatment significantly decreased tau hyperphosphorylation, reducing AT8-IR to levels even lower than those observed in gonadally intact $3 \mathrm{xTg}$-AD mice. These observations are generally consistent with previous studies demonstrating that E2 and $\mathrm{P} 4$ can modulate activities of kinases involved in regulating tau phosphorylation, including glycogen synthase kinase-3 $\beta$ (GSK-3 $\beta$ ) (Alvarez-de-la-Rosa et al., 2005; Goodenough et al., 2005). Specifically, E2 has been reported to reduce GSK-3 $\beta$ activity (Goodenough et al., 2005), a kinase that phosphorylates tau sites associated with neuropathology (Ishizawa et al., 2003). Recent data suggest that acute P4 treatment can decrease expression of both tau and GSK- $3 \beta$ in rat cerebellum, but net increases in both GSK-3 $\beta$ activity and tau phosphorylation were also observed (Guerra-Araiza et al., 2007). It is unclear how continuous P4 affects GSK-3 $\beta$, although our data predict that extended $\mathrm{P} 4$ exposure alters the balance of taurelevant kinase and phosphatase activities to yield a net decrease in pathological tau phosphorylation. Interestingly, previous studies have demonstrated that GSK- $3 \beta$-dependent regulation of tau hyperphosphorylation is related to behavioral performance in 3xTg-AD mice (Billings et al., 2007), which suggests a potentially important connection between the effects of progesterone on tau hyperphosphorylation and cognition in AD patients.

The results of this study also provide interesting insight into the relationships between $\mathrm{A} \beta$ accumulation, tau hyperphospho- 

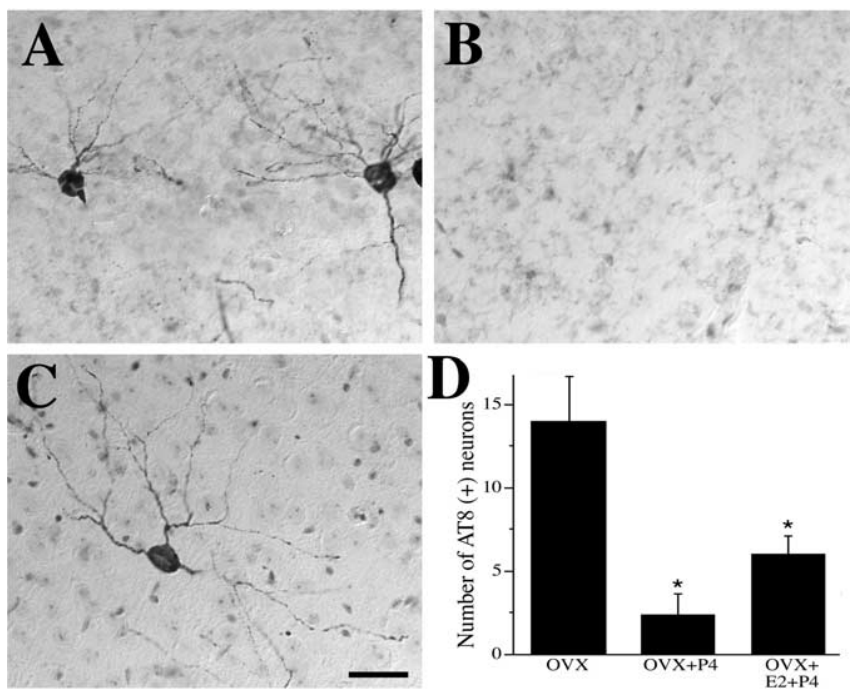

Figure 10. P4 regulates tau hyperphosphorylation. Representative images of AT8-IR (counterstained with cresyl violet) show neurons with abnormal tau phosphorylation in female 3XTg-AD mice at age 6 months in the $\mathrm{OVX}(\boldsymbol{A}), \mathrm{OVX}+\mathrm{P} 4(\boldsymbol{B})$, and $\mathrm{OVX}+\mathrm{E} 2+\mathrm{P} 4(\boldsymbol{C})$ conditions. Scale bar, $50 \mu \mathrm{m}$. D, Quantification of numbers of intensely AT8-immunoreactive cells in hippocampus $C A 1$ and subiculum show that $P 4$ treatments significantly decreased tau hyperphosphorylation compared with the $\mathrm{OVX}$ group $(F=9.71, p=0.002) .{ }^{*} p<0.05$ relative to OVX group.

rylation, and behavioral impairment. In gonadally intact $3 \mathrm{xTg}-\mathrm{AD}$ females, we found a strong negative association between the progression of $\mathrm{A} \beta$ accumulation in hippocampus CA1 and subiculum and performance in the hippocampal-dependent SAB task. In addition, we observed a correlation between E2mediated changes in $A \beta$ accumulation and behavioral impairment, additional evidence of a cause-and-effect relationship between these two pathologies. However, combined E2+P4 treatment revealed that behavioral impairments in the $3 \times \mathrm{Tg}-\mathrm{AD}$ mouse are not simply a function of $\mathrm{A} \beta$ load. Combined $\mathrm{E} 2+\mathrm{P} 4$ treatment did not decrease $A \beta$ load yet reduced tau hyperphosphorylation and significantly improved SAB performance, suggesting that the relationship between tau hyperphosphorylation and behavioral impairment is presumably dependent on interactions with $\mathrm{A} \beta$ accumulation. For example, despite strongly reducing AT8 immunoreactivity, independent P4 treatment did not significantly affect either $\mathrm{A} \beta$ load or SAB performance. These results are consistent with recent observations by Oddo et al. (2006b) that improving behavioral performance in the $3 \times \mathrm{Tg}-\mathrm{AD}$ mouse model by $A \beta$ immunotherapy strategies required not only decreasing soluble $A \beta$ levels but also lowering soluble tau levels. Together, these results suggest that behavioral impairment in $3 x T g-A D$ mice involves both $\mathrm{A} \beta$ accumulation and tau hyperphosphorylation, pathologies that are differentially affected by E2 and $\mathrm{P} 4$ treatments.

In summary, the results of this study provide novel insights into the roles of estrogen and progesterone in regulating $\mathrm{AD}$ neuropathology. Although HT use in postmenopausal women can significantly reduce the risk of developing AD (Paganini-Hill and Henderson, 1996; Tang et al., 1996; Kawas et al., 1997; Hogervorst et al., 2000; Zandi et al., 2002; Maki, 2005), the recent WHIMS study has raised several important issues that may significantly affect the efficacy of HT, including the estrogen and progestogen composition of treatment, the timing of treatment initiation, and cyclic versus continuous application of treatment hormones (Brinton, 2004; Craig et al., 2005). Our findings in an animal model of $\mathrm{AD}$ support the hypothesis that the loss of sex steroid hormones promotes development of AD neuropathology and that hormone treatments can effectively reduce this effect. Our results are also consistent with the complex, seemingly conflicting clinical data, which indicate both apparent benefits and risks with $\mathrm{HT}$ use in women. In the $3 \mathrm{xTg}-\mathrm{AD}$ mouse, our results indicate that continuous $\mathrm{E} 2$ treatment combats $\mathrm{A} \beta$ accumulation and behavioral impairments. However, continuous $\mathrm{P} 4$ treatment had both a positive effect, reduction of tau hyperphosphorylation, and a negative outcome, attenuation of $\mathrm{A} \beta$ lowering by $\mathrm{E} 2$. Additional studies are needed to not only elucidate the relationships between estrogen and progesterone interactions but also to optimize the ability of E2 and P4 treatments to reduce AD-like neuropathology. We believe that the continued evaluation of hormone treatments in animal models of $\mathrm{AD}$ will yield important insights into the design of future HT regimens that will safely and effectively reduce the development of $\mathrm{AD}$ in postmenopausal women.

\section{References}

Alkayed NJ, Murphy SJ, Traystman RJ, Hurn PD, Miller VM (2000) Neuroprotective effects of female gonadal steroids in reproductively senescent female rat. Stroke 31:3041-3046.

Alvarez-de-la-Rosa M, Silva I, Nilsen J, Perez MM, Garcia-Segura LM, Avila J, Naftolin F (2005) Estradiol prevents neural tau hyperphosphorylation characteristic of Alzheimer's disease. Ann NY Acad Sci 1052:210-224.

Azcoitia I, Fernandez-Galaz C, Sierra A, Garcia-Segura LM (1999) Gonadal hormones affect neuronal vulnerability to excitotoxin-induced degeneration. J Neurocytol 28:699-710.

Billings LM, Green KN, McGaugh JL, LaFerla FM (2007) Learning decreases $\mathrm{A} \beta^{\star} 56$ and tau pathology and ameliorates behavioral decline in $3 \times \mathrm{Tg}-\mathrm{AD}$ mice. J Neurosci 27:751-761.

Bimonte-Nelson HA, Nelson ME, Granholm AC (2004) Progesterone counteracts estrogen-induced increases in neurotrophins in the aged female rat brain. NeuroReport 15:2659-2663.

Bimonte-Nelson HA, Francis KR, Umphlet CD, Granholm AC (2006) Progesterone reverses the spatial memory enhancements initiated by tonic and cyclic oestrogen therapy in middle-aged ovariectomized female rats. Eur J Neurosci 24:229-242.

Brinton RD (2004) Impact of estrogen therapy on Alzheimer's disease: a fork in the road? CNS Drugs 18:405-422.

Craig MC, Maki PM, Murphy DG (2005) The Women's Health Initiative Memory Study: findings and implications for treatment. Lancet Neurol 4:190-194.

Cummings BJ, Mason AJ, Kim RC, Sheu PC, Anderson AJ (2002) Optimization of techniques for the maximal detection and quantification of Alzheimer's-related neuropathology with digital imaging. Neurobiol Aging 23:161-170.

De Nicola AF, Gonzalez SL, Labombarda F, Deniselle MC, Garay L, Guennoun R, Schumacher M (2006) Progesterone treatment of spinal cord injury: effects on receptors, neurotrophins, and myelination. J Mol Neurosci 28:3-15

Espeland MA, Rapp SR, Shumaker SA, Brunner R, Manson JE, Sherwin BB, Hsia J, Margolis KL, Hogan PE, Wallace R, Dailey M, Freeman R, Hays J (2004) Conjugated equine estrogens and global cognitive function in postmenopausal women: Women's Health Initiative Memory Study. JAMA 291:3005-3007.

Franklin KBJ, Paxinos G (1997) The mouse brain in stereotaxic coordinates. San Diego: Academic.

Goedert M, Jakes R, Vanmechelen E (1995) Monoclonal antibody AT8 recognizes tau protein phosphorylated at both serine 202 and threonine 205. Neurosci Lett 189:167-169.

Goodenough S, Schleusner D, Pietrzik C, Skutella T, Behl C (2005) Glycogen synthase kinase 3 beta links neuroprotection by 17 beta-estradiol to key Alzheimer processes. Neuroscience 132:581-589.

Gibbs RB (2000) Effects of gonadal hormone replacement on measures of basal forebrain cholinergic function. Neuroscience 101:931-938.

Green PS, Bales K, Paul S, Bu G (2005) Estrogen therapy fails to alter amyloid deposition in the PDAPP model of Alzheimer's disease. Endocrinology 146:2774-2781. 
A

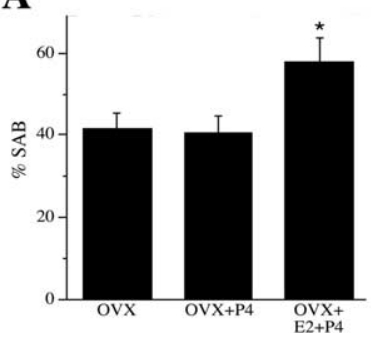

B

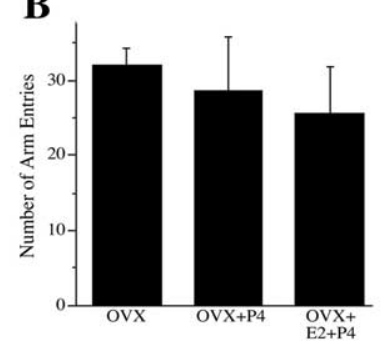

C

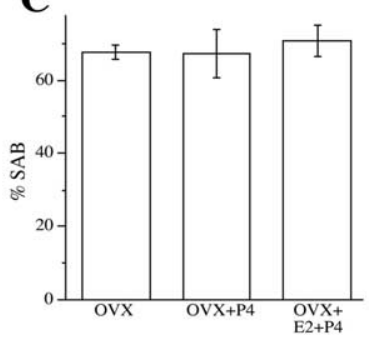

Figure 11. P4 regulation of spontaneous alternation behavior. Progesterone treatment did not significantly affect SAB performance in either 6-month-old female 3xTg-AD mice or in age-matched WT female mice. $A$, Compared with the OVX group of $3 x T g$-AD mice, $P 4$ significantly improved the impaired $S A B$ performance only when cotreated with $E 2(F=4.36, p=0.03)$. ${ }^{*} p<$ 0.05 relative to OVX. $B$, The number of arm entries in the task did not significantly differ across $3 \times \mathrm{Tg}$ - $\mathrm{AD}$ treatment groups $(F=$ $0.37, p=0.70) . C$, In WT mice, there were no significant differences in SAB performance across OVX, OVX $+\mathrm{P} 4$, and OVX $+\mathrm{E} 2+\mathrm{P} 4$ $\operatorname{groups}(F=1.68, p=0.22)$.

Guerra-Araiza C, Amorim MA, Camacho-Arroyo I, Garcia-Segura LM (2007) Effects of progesterone and its reduced metabolites, dihydroprogesterone and tetrahydroprogesterone, on the expression and phosphorylation of glycogen synthase kinase- 3 and the microtubule-associated protein tau in the rat cerebellum. Dev Neurobiol 67:510-520.

Hardy J, Selkoe DJ (2002) The amyloid hypothesis of Alzheimer's disease: progress and problems on the road to therapeutics. Science 297:353-356.

Heikkinen T, Kalesnykas G, Rissanen A, Tapiola T, Iivonen S, Wang J, Chaudhuri J, Tanila H, Miettinen R, Puolivali J (2004) Estrogen treatment improves spatial learning in APP + PS1 mice but does not affect beta amyloid accumulation and plaque formation. Exp Neurol 187:105-117.

Hoffman GE, Moore N, Fiskum G, Murphy AZ (2003) Ovarian steroid modulation of seizure severity and hippocampal cell death after kainic acid treatment. Exp Neurol 182:124-134.

Hogervorst E, Williams J, Budge M, Riedel W, Jolles J (2000) The nature of the effect of female gonadal hormone replacement therapy on cognitive function in post-menopausal women: a meta-analysis. Neuroscience 101:485-512.

Ishizawa T, Sahara N, Ishiguro K, Kersh J, McGowan E, Lewis J, Hutton M, Dickson DW, Yen SH (2003) Co-localization of glycogen synthase kinase-3 with neurofibrillary tangles and granulovacuolar degeneration in transgenic mice. Am J Pathol 163:1057-1067.

Kadish I, Van Groen T (2002) Low levels of estrogen significantly diminish axonal sprouting after entorhinal cortex lesions in the mouse. J Neurosci 22:4095-4102.

Kawas C, Resnick S, Morrison A, Brookmeyer R, Corrada M, Zonderman A, Bacal C, Lingle DD, Metter E (1997) A prospective study of estrogen replacement therapy and the risk of developing Alzheimer's disease: the Baltimore Longitudinal Study of Aging. Neurology 48:1517-1521.

King DL, Arendash GW (2002) Behavioral characterization of the Tg2576 transgenic model of Alzheimer's disease through 19 months. Physiol Behav 75:627-642.

Levin-Allerhand JA, Lominska CE, Wang J, Smith JD (2002) 17Alphaestradiol and 17beta-estradiol treatments are effective in lowering cerebral amyloid-beta levels in AbetaPPSWE transgenic mice. J Alzheimers Dis 4:449-457.

Maki PM (2005) A systematic review of clinical trials of hormone therapy on cognitive function: effects of age at initiation and progestin use. Ann NY Acad Sci 1052:182-197.

Oddo S, Caccamo A, Kitazawa M, Tseng BP, LaFerla FM (2003a) Amyloid deposition precedes tangle formation in a triple transgenic model of Alzheimer's disease. Neurobiol Aging 24:1063-1070.

Oddo S, Caccamo A, Shepherd JD, Murphy MP, Golde TE, Kayed R, Metherate R, Mattson MP, Akbari Y, LaFerla FM (2003b) Triple-transgenic model of Alzheimer's disease with plaques and tangles: intracellular Abeta and synaptic dysfunction. Neuron 39:409-421.

Oddo S, Caccamo A, Tran L, Lambert MP, Glabe CG, Klein WL, LaFerla FM (2006a) Temporal profile of amyloid- $\beta(\mathrm{A} \beta)$ oligomerization in an in vivo model of Alzheimer disease. J Biol Chem 281:1599-1604.

Oddo S, Vasilevko V, Caccamo A, Kitazawa M, Cribbs DH, LaFerla FM (2006b) Reduction of soluble Abeta and tau, but not soluble Abeta alone,

ameliorates cognitive decline in transgenic mice with plaques and tangles. J Biol Chem 281:39413-39423.

Paganini-Hill A, Henderson VW (1994) Estrogen deficiency and risk of Alzheimer's disease in women. Am J Epidemiol 140:256-261.

Paganini-Hill A, Henderson VW (1996) Estrogen replacement therapy and risk of Alzheimer disease. Arch Intern Med 156:2213-2217.

Petanceska SS, Nagy V, Frail D, Gandy S (2000) Ovariectomy and 17beta-estradiol modulate the levels of Alzheimer's amyloid beta peptides in brain. Exp Gerontol 35:1317-1325.

Pike CJ (1999) Estrogen modulates neuronal $\mathrm{Bcl}-\mathrm{xL}$ expression and beta-amyloid-induced apoptosis: relevance to Alzheimer's disease. J Neurochem 72:1552-1563.

Pomp D, Geisert RD, Durham CM, Murray JD (1995) Rescue of pregnancy and maintenance of corpora lutea in infertile transgenic mice expressing an ovine metallothionein la-ovine growth hormone fusion gene. Biol Reprod 52:170-178.

Rapp SR, Espeland MA, Shumaker SA, Henderson VW, Brunner RL, Manson JE, Gass ML, Stefanick ML, Lane DS, Hays J, Johnson KC, Coker LH, Dailey M, Bowen D (2003) Effect of estrogen plus progestin on global cognitive function in postmenopausal women: the Women's Health Initiative Memory Study: a randomized controlled trial. JAMA 289:2663-2672.

Roof RL, Duvdevani R, Braswell L, Stein DG (1994) Progesterone facilitates cognitive recovery and reduces secondary neuronal loss caused by cortical contusion injury in male rats. Exp Neurol 129:64-69.

Rosario ER, Ramsden M, Pike CJ (2006a) Progestins inhibit the neuroprotective effects of estrogen in rat hippocampus. Brain Res 1099:206-210.

Rosario ER, Carroll JC, Oddo S, LaFerla FM, Pike CJ (2006b) Androgens regulate the development of neuropathology in a triple transgenic mouse model of Alzheimer's disease. J Neurosci 26:13384-13389.

Shultz JM, Zhu XD, Knopp RH, Leboeuf RC, Rosenfeld ME (2004) Norgestimate and medroxyprogesterone acetate do not attenuate the atheroprotective effects of 17beta-estradiol in ovariectomized, apolipoprotein E-deficient mice. Fertil Steril 82 [Suppl 3]:1133-1139.

Shumaker SA, Legault C, Rapp SR, Thal L, Wallace RB, Ockene JK, Hendrix SL, Jones BN, Assaf AR, Jackson RD, Kotchen JM, Wassertheil-Smoller S, Wactawski-Wende J (2003) Estrogen plus progestin and the incidence of dementia and mild cognitive impairment in postmenopausal women: the Women's Health Initiative Memory Study: a randomized controlled trial. JAMA 289:2651-2662.

Slater CC, Zhang C, Hodis HN, Mack WJ, Boostanfar R, Shoupe D, Paulson RJ, Stanczyk FZ (2001) Comparison of estrogen and androgen levels after oral estrogen replacement therapy. J Reprod Med 46:1052-1056.

Tang MX, Jacobs D, Stern Y, Marder K, Schofield P, Gurland B, Andrews H, Mayeux R (1996) Effect of oestrogen during menopause on risk and age at onset of Alzheimer's disease. Lancet 348:429-432.

Toung TJ, Chen TY, Littleton-Kearney MT, Hurn PD, Murphy SJ (2004) Effects of combined estrogen and progesterone on brain infarction in reproductively senescent female rats. J Cereb Blood Flow Metab 24:1160-1166.

Walsh DM, Klyubin I, Shankar GM, Townsend M, Fadeeva JV, Betts V, Podlisny MB, Cleary JP, Ashe KH, Rowan MJ, Selkoe DJ (2005) The role of cell-derived oligomers of Abeta in Alzheimer's disease and avenues for therapeutic intervention. Biochem Soc Trans 33:1087-1090.

West MJ, Slomianka L, Gundersen HJG (1991) Unbiased stereological estimation of the total number of neurons in the subdivisions of the rat hippocampus using optical fractionator. Anat Rec 231:482-497.

Yue X, Lu M, Lancaster T, Cao P, Honda S, Staufenbiel M, Harada N, Zhong Z, Shen Y, Li R (2005) Brain estrogen deficiency accelerates Abeta plaque formation in an Alzheimer's disease animal model. Proc Natl Acad Sci USA 102:19198-19203.

Zandi PP, Carlson MC, Plassman BL, Welsh-Bohmer KA, Mayer LS, Steffens DC, Breitner JC (2002) Hormone replacement therapy and incidence of Alzheimer disease in older women: the Cache County Study. JAMA 288:2123-2129.

Zheng H, Xu H, Uljon SN, Gross R, Hardy K, Gaynor J, Lafrancois J, Simpkins J, Refolo LM, Petanceska S, Wang R, Duff K (2002) Modulation of A(beta) peptides by estrogen in mouse models. J Neurochem 80:191-196. 